\title{
SHAPE MEMORY AND SUPERELASTICITY BEHAVIOUR OF POROUS Ti-Ni MATERIAL
}

\author{
I. MARTYNOVA, V. SKOROHOD, S. SOLONIN and S. GONCHARUK \\ Institute for Problems of Materials Science, Ukr. Acad. of Sci, Krzijanovsky str. 3, Kiev 252680, USSR
}

\begin{abstract}
The peculiarities of shape memory and superelasticity effects in porous $\mathrm{Ti}-\mathrm{Ni}$ were studied both for powder technology stages of production and deformation of sintered porous material.

It is shown that porous $\mathrm{T} i-\mathrm{Ni}$ material demonstrates new functional capacities in comparison with nonporous one: wider range of permissible deformation, increasing of reversible deformation and "volume memory" effect.
\end{abstract}

\section{Introduction}

In the recent years a number of fundamental investigations of the shape memory (SME) and superelasticity effects were carried out $(1,2)$. The main subject of these studies were compact materials (mainly TiNi and copper-based alloys) produced by melting with subsequent plastic working and temperature treatment. So, the advantages of the powder metallurgy methods were not adequately used for these materials. However, this technology gives new perspectives both in manufacturing and obtaining products with essentially new properties. The subject of this work was the investigation of SME and superelasticity of porous $\mathrm{Ti}-\mathrm{Ni}$ material both in the consecutive technological stages (compaction, sintering) of production and in the deformation process.

\section{Material investigated}

Being investigated was prealloyed $\mathrm{Ti}-\mathrm{Ni}$ material, containing 56 wt $\%$ of nickel and up to 0.55 wt \% of oxygen.

The temperature hysteresis of martensitic transformation of this material was determined using low temperature $X$-ray analysis within the temperature range $-180 \div+100^{\circ} \mathrm{C}$. It showed an extremely extended 
transformation interval which can be probably explained by the oxygen impurity influence and local chemical inhomogeneity of the powder. caused by the production technology.

\section{Compaction}

Prealloyed $\mathrm{Ti}-\mathrm{Ni}$ powder was compacted at ambient temperature in 10 $\mathrm{mm}$ mould with the various given values of pressure from $12.5 \mathrm{MPa}$ to $1000 \mathrm{MPa}$. The diagrams of loading-unloading for each case were recorded with the aid of INSTRON testing machine. Due to superelasticity effect afteraction on unloading significantly exceeds the usual elastic afteraction of the powder compacts. The deformation temperature for the investigated material is inside the hysteresis loop, so only the part of the amount of martensite, formed under the deformation, undergoes the reverse deformation on unloading.

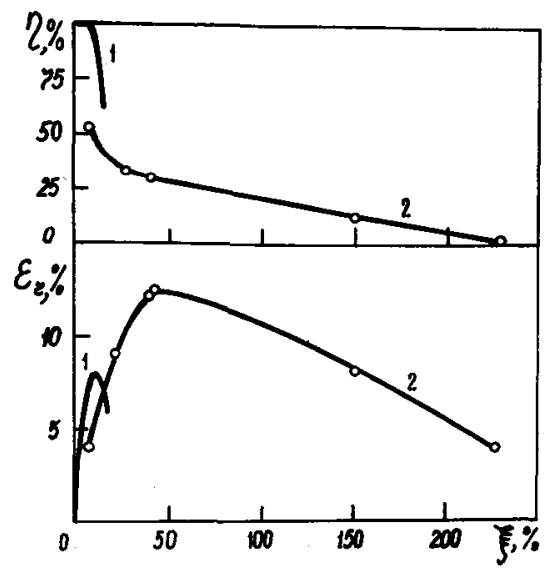

Fig. 1. Height recovery degree ( $\eta$ ) and reversible deformation $\left(\varepsilon_{r}\right)$ vs direct deformation ( $\xi$ ) for nonporous TiNi in tension (1) and Ti-Ni powder under compaction.

Shown in fig. 1. are the dependencies of height recovery degree ( $\eta$ ) and reversible deformation $(\varepsilon)$ on direct deformation $(\xi)$. These characteristics were calculated as following:

$$
\xi=\frac{h_{0}-h_{1}}{h_{1}} ; \quad \varepsilon_{r}=\frac{h_{u 1}-h_{1}}{h_{1}} ; \quad \eta=\frac{\varepsilon_{r}}{\xi}=\frac{h_{u 1}-h_{1}}{h_{0}-h_{1}} .
$$

where $h_{0}$ - the height of powder in the mould before compaction $\mathrm{mm}$ ) ;

$h_{1}$ - the height of powder in the mould under the applied load; $h_{u l}$ - the height of compact in the mould after unloading. 
Along with data for powder specimens in fig. 1 the analogous characteristics for nonporous TiNi in tension (3) are given for comparison, but this comparison is rather provisional.

One can see three characteristic features of the curves shown in

fig. 1::

- the degree of the height recovery in one compaction cycle doesn't achieve 100\%;

- the reversible deformation of porous material significantly exceeds that of nonporous one;

- the position of maximum of the reverse deformation versus direct one for porous specimens is shifted to higher values of direct deformation.

These peculiarities of superelasticity behavior of porous $\mathrm{Ti}-\mathrm{Ni}$ material are associated with the general regularities of porous body deformation. Its main feature is heterogeneity, i.e. localization of deformation and noncoincidence of macroscopic deformation value of porous body as a whole with the averaged value of metal matrix deformation.

Therefore in the case of porous material the reversibie deformation due to stress-induced martensite transformation and martensitic reorientation coexist with the irreversible plastic flow even for the least values of macroscopic deformation.

Deformation of a porous material is accompanied by the macroscopic volume changes. It means that the shape recovery in the metal matrix provides the recovery of the initial volume of porous body, i.e. "volume memory" effect.

The volume increase also takes place after extraction of sample from the mould and $c a n$ reach $\simeq 24 \%$ due to release from friction forces at the side surface of the compact.

\section{Sintering}

Volume increase continues under the heating necessary for sintering due to SME. The most intensive volume growth is observed up to $200^{\circ} \mathrm{C}$. In the $200-400^{\circ} \mathrm{C}$ interval the compact volume is constant and over $1000^{\circ} \mathrm{C}$ shrinkage of sample is observed. The volume growth as well as recovery degree, which is shown in fig. 2 .. is the less, the less is the porosity, because of greater lattice distortions and porous material strength. Here the recovery degree was calculated as:

$$
\eta_{v}=\frac{v_{t}-v_{1}}{v_{0}-v_{1}}
$$

where $V_{t}$ - specimen volume at the given temperature;

$V_{1}$ - compact volume under the applied load in the mould;

$v_{0}$ - apparent porosity of the powder. 


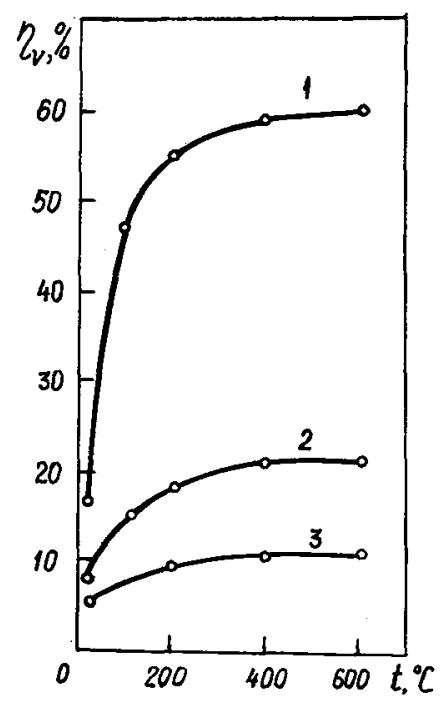

Fig. 2. Temperature dependence of the volume recovery degree under the applied load for compacts of different porosity: $61.3 \%$ (1); $40.6 \%$ (2) ; $19.7 \%$ (3).

5. SME and superelasticity of sintered porous material

Sintered porous cylindrical samples were deformed by compression, the loading diagram being recorded by testing machine. The character of dependencies of reversible deformation on direct one is similar (fig. 3.) to that for initial powder.

The curves are obtained from the data of height change of the sintered specimens under loading and unloading.

The maximum value and its position are changing with the sample porosity, increasing in both coordinates for higher porosity. These curves are formed as a result of common contribution of two deformation channels. One of them is martensitic transformation, which provides an increase of the reversible deformation, and the second is the deformation in accordance with traditional mechanisms of plastic flow, which decreases the reversible deformation. This is also the reason of decreasing of the recovery degree.

It should be noted that after few loading-unloading cycles each sample demonstrates almost $100 \%$ recovery, achieved in the last cycle. The number of necessary cycles is different for various sample porosities and applied loads. Such cycling, however, leads to decreasing of the reversible deformation value (table 1.$)$. 
Table 1.

Superelasticity of porous $\mathrm{Ti}-\mathrm{Ni}$ under uniaxial compression.

\begin{tabular}{|c|c|c|c|c|c|}
\hline $\begin{array}{c}\text { Porosity, } \\
\%\end{array}$ & $\begin{array}{c}\text { Pressure, } \\
\mathrm{MPa}\end{array}$ & $\begin{array}{l}\text { Reversible } \\
\text { deformati- } \\
\text { on in the } \\
\text { first loa- } \\
\text { ding cy- } \\
\text { cle, } \%\end{array}$ & $\begin{array}{l}\text { Number of } \\
\text { cycles, } \\
\text { necessary } \\
\text { for com- } \\
\text { plete } \\
\text { height } \\
\text { recovery } \\
\text { in one } \\
\text { cycle }\end{array}$ & $\begin{array}{c}\text { Reversible } \\
\text { deformati- } \\
\text { on after } \\
\text { cycling. } \\
\%\end{array}$ & $\begin{array}{l}\text { Compression } \\
\text { strength, } \\
\text { MPa }\end{array}$ \\
\hline 30 & $400 \div 800$ & $8 \div 7$ & 13 & 5.5 & 1400 \\
\hline 43 & $300 \div 600$ & $10.5 \div 9$ & $14 \div 17$ & $7.5 \div 7$ & 1000 \\
\hline 50 & $100 \div 300$ & $12.5 \div 10$ & $11 \div 19$ & $9 \div 8$ & 500 \\
\hline
\end{tabular}

Given in the table 1. are also the recommended pressures, corresponding to the highest superelasticity characteristics for materials with different porosities.

After heating additional reversible macroscopic deformation increase can reach $20 \%$.

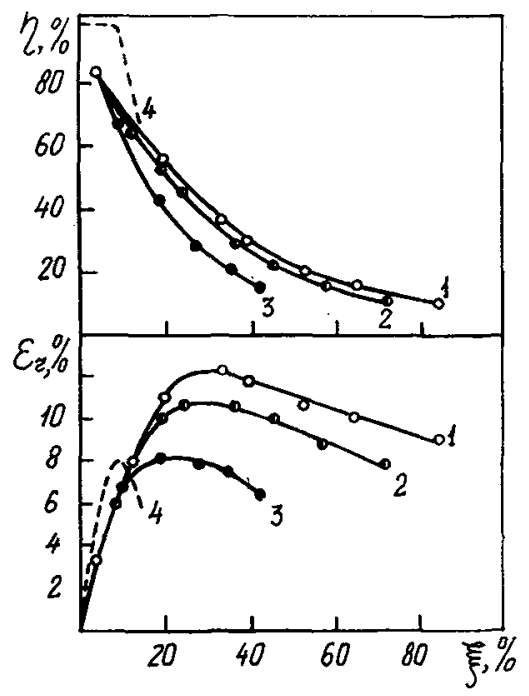

Fig. 3. Height recovery degree ( $\eta)$ and reversible deformation ( $\left.\varepsilon_{r}\right)$ for sintered specimens with different porosity: $50 \%$ (1); $43 \%$ (2); $30 \%$ (3) vs direct deformation ( $(\xi)$ under uniaxial compression.

The dotted curve is the same for nonporous TiNi under tension. 


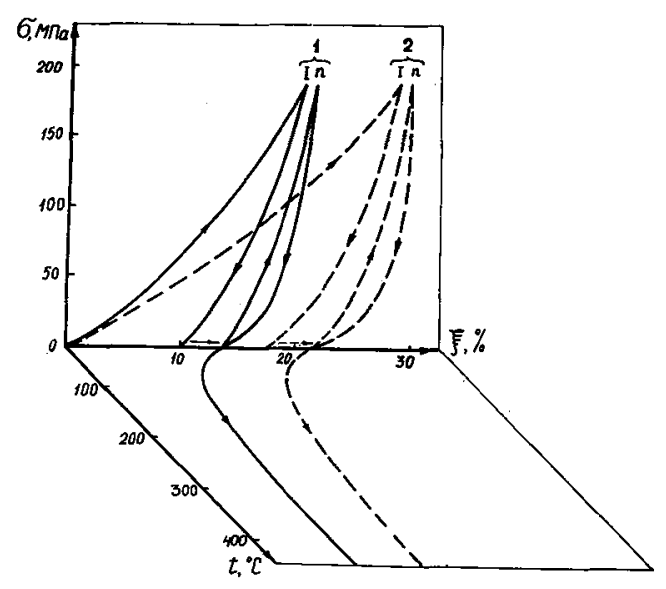

Fig. 4. Mechanical-temperature diagram for sintered material of $43 \%$ (1) and $50 \%$ (2) porosities in coordinates: compression pressure (G) axial deformation $(\xi)$ - temperature $(t)$.

n - cycle number for achieving $100 \%$ recovery.

Fig. 4. shows the summarized data for sintered samples with $43 \%$ and $50 \%$ porosity after mechanical and temperature treatment. Plotted at this diagram is the ratio between reversible and irreversible parts of deformation on loading at the ambient temperature and subsequent heating. It can be seen that temperature dependent part reaches saturation at the lower temperatures for the lower porosity and for equal porosities at the lower pressure.

Thus. Ti-Ni as a porous material expands the functional capacities of the SME alloys due to wider range of permissible macroscopic deformations, increasing of the reversible deformation and usage of the "volume memory" effect.

Besides that, powder metallurgy methods are useful in manufacturing of complex shape parts.

11/ Proceedings of International Conference on Martensitic Transformation ICOMAT-82, Leuven (Belgium) (1982), ed. by L.Delaye, M.Chandrasekaran.

/2/ Splawy s effektom pamyati formy / K.otsuka, K.Shimizu, Y.Suzuki et. al. Trans. from Jap., Moskwa, Metallurgiya (1990).

13/ Apaew B.A., Woronenko B.I., Metallowedenie i termicheskaya obrabotka metallow, Moskwa 1 (1973) 24. 